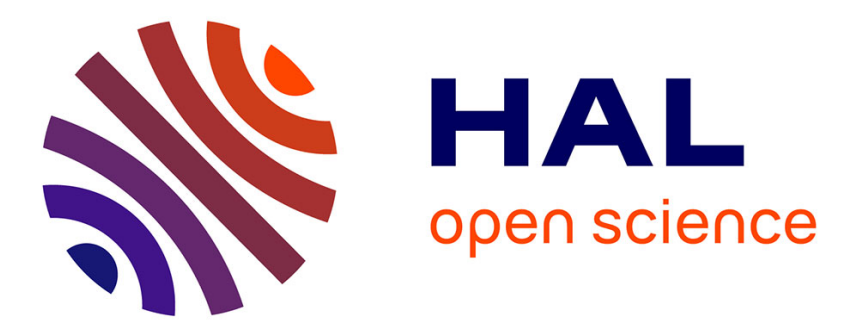

\title{
The use of phylogenetic diversity in conservation biology and community ecology: A common base but different approaches
}

Simon Veron, Victor Saito, Nélida Padilla-García, Félix Forest, Yves Bertheau

\section{- To cite this version:}

Simon Veron, Victor Saito, Nélida Padilla-García, Félix Forest, Yves Bertheau. The use of phylogenetic diversity in conservation biology and community ecology: A common base but different approaches. Quarterly Review of Biology, 2019, 94 (2), pp.123-148. 10.1086/703580 . hal-02290915

\section{HAL Id: hal-02290915 https://hal.sorbonne-universite.fr/hal-02290915}

Submitted on 18 Sep 2019

HAL is a multi-disciplinary open access archive for the deposit and dissemination of scientific research documents, whether they are published or not. The documents may come from teaching and research institutions in France or abroad, or from public or private research centers.
L'archive ouverte pluridisciplinaire HAL, est destinée au dépôt et à la diffusion de documents scientifiques de niveau recherche, publiés ou non, émanant des établissements d'enseignement et de recherche français ou étrangers, des laboratoires publics ou privés. 
1 *H1THE USE OF PHYLOGENETIC DIVERSITY IN CONSERVATION BIOLOGY AND

2 COMMUNITY ECOLOGY: A COMMON BASE BUT DIFFERENT APPROACHES

3

$4 *$ A1Simon Veron

5

6 *A2Institut de Systématique Evolution et Biodiversité (ISYEB UMR7205), Sorbonne

7 Universités, MNHN, CNRS, UPMC, CP51

8

975005 Paris, France

10

$11 *$ *SC2e-mail: sveron@edu.mnhn.fr

12

$13 *$ A1Victor Saito

14

15 *A2Departamento de Ciências Ambientais, Universidade Federal de São Carlos

16

17 São Carlos, Brazil

18

19 *SC2e-mail: victor.saito@gmail.com

20

$21 *$ *A1Nélida Padilla-García

22

23 *A2Centre d'Ecologie et des Sciences de la Conservation (CESCO UMR7204) MNHN, CP51

24

2575005 Paris, France 
$27 *$ A2Departamento de Botánica, University of Salamanca

28

29 E-37007 Salamanca, Spain

30

$31 *$ S2e-mail: nelidapg@gmail.com

32

$33 *$ *1Félix Forest

34

$35 *$ *2Jodrell Laboratory, Royal Botanic Gardens

36

37 Kew, Richmond TW9 3DS United Kingdom

38

39 *SC2e-mail: F.Forest@kew.org

40

$41 *$ A1Yves Bertheau

42

43 *A2Centre d'Ecologie et des Sciences de la Conservation (CESCO UMR7204) MNHN, CP51

44

4575005 Paris, France

46

47 *A2Institut National de la Recherche Agronomique (INRA)

48

4978026 Versailles cedex, France

50 
55 phylogenetic diversity, ecosystem services, evolutionary potential, feature variation, option values, spatial planning

$58 *$ AB1abstract

$60 *$ AB2The use of phylogenetic tools and studies has strongly increased in the last two 61 decades especially in conservation biology and community ecology. Phylogenetic trees have been

62 essential to understand the processes of community or network assembly, to identify centers of

63 diversification, and to help protect Earth's evolutionary heritage. Despite two decades of research

64 and syntheses, there are still many discussions on how phylogenetic diversity (PD) methods

65 should be effectively applied to those fields. In particular, conservation approaches based on PD

66 have become similar to these used in community ecology. Thus, the main benefit of using PD

67 calculations in conservation biology may have been ignored or misinterpreted. Our goal is to

68 discuss and provide guidelines to the use of PD in biodiversity conservation so that its benefits

69 are not hidden or lost in the approaches employed. We also aim that benefits and uses are better

70 recognized and more easily understood by researchers or practitioners who would like to include

71 PD in their studies and conservation planning.

$73 *$ S1Introduction 
$75 *$ T1The development of humanity has impacted Earth, causing damage to ecosystems, species

76 extinction, and habitat loss that — among the many potential impacts — may in turn threaten

77 human societies. It has become urgent to establish appropriate actions that could mitigate this

78 "crisis" affecting humankind. However, conserving representative populations of all species is

79 generally perceived to be unrealistic due to limited resources and, therefore, effective decisions

80 are needed to best protect biodiversity. Conservation strategies based on species richness and

81 abundance (which aim to preserve species and habitats at a broad scale) have been the rule rather

82 than the exception. For example, the influential "hotspots" of biodiversity have been identified

83 based on endemic and threatened species (Myers et al. 2000). Moreover, these approaches were

84 easier to implement than those based on functions or phylogenies (e.g., no need to collect time-

85 consuming and expensive traits or molecular data nor to estimate functional/phylogenetic

86 relationships between species). However, approaches that consider all species as equal are limited

87 when conservation priorities have to be defined because they fail to recognize their

88 distinctiveness (Avise 1989; Vane-Wright et al. 1991; Faith 1992). On the contrary, progress in

89 phylogenetic inference has enabled the prioritization of conservation efforts based on the

90 evolutionary history of species (Mace et al. 2003). Similarly, in community ecology and

91 biogeography, considering all species ecologically equal is inherent to neutral hypotheses

92 (Hubbell et al. 2001), whereas other methodologies, such as phylogenetic approaches, consider

93 that species assemblage may be guided by species niches (Webb et al. 2002).

94 In the 1980s, the International Union for the Conservation of Nature (IUCN) emphasized

95 the interest of taxonomic distinctiveness for conservation by stating that "the greater the gap

96 between the nearest related family (or genus) ... and therefore the more distinct" (IUCN

97 1980:22; Faith 2016a, 2018a). From this, "taxonomic hierarchy provides the only convenient rule

98 of thumb for determining the relative size of a potential loss of genetic material" because

99 "different positions in this hierarchy reflect great or lesser degrees of genetic difference" (IUCN 
100 1980:22). The significance of the taxonomic distinctiveness concept prompted its use by several

101 state agencies in Australia at the end of the 1980s and through research in systematics and

102 conservation biology (Avise 1989; Faith 1994, 2018a). Quantitative measures of taxonomic

103 distinctiveness for conservation originated in the 1990s with studies from May (1990) and Vane-

104 Wright et al. (1991). Vane-Wright et al. (1991) introduced a measure of taxonomic distinctness

105 that ranks species according to the number of cladistic groups they belong to, a perspective that

106 was later refined by other authors (e.g., Erwin 1991; Brooks et al. 1992; Crozier 1992; Faith

107 1992, 1994; Weitzman 1992; Crozier and Kusmierski 1994; Williams and Humphries 1994;

108 Witting and Loeschcke 1995). However, taxonomic distinctiveness did not allow for the ability to

109 measure the diversity of a set of species (Vane-Wright et al. 1991). Faith (1992) proposed to link

110 diversity and distinctiveness by introducing the notion of phylogenetic diversity (PD) as the sum

111 of the branch lengths of the minimum spanning path joining a set of taxa on a tree. Phylogenetic

112 diversity is assumed to represent the relative feature diversity of organisms so that maximizing

113 PD may be a sound strategy for conservation because it would, on average, maximize the

114 protection of feature diversity (a "feature" is a particular trait characteristic of a taxa). Due to

115 their high number and because many are unknown, all taxon features cannot usually be accounted

116 for (Faith 1992, 1994, 2016a; Pavoine et al. 2005). This relation was based on an evolutionary

117 model in which shared features are inherited from shared ancestry (Faith 1992), which was later

118 shown to have important implications not only in conservation, but also in community ecology

119 and biogeography (e.g., Webb et al. 2002; Gerhold et al. 2015; Saito et al. 2018). Indeed, this

120 assumption resulted in the use of phylogenetic information to unravel the process at the origin of

121 diversity patterns and community assembly (Webb et al. 2002; Davies et al. 2011). For example,

122 it was hypothesized that the occurrence of distantly related species in a given area might indicate

123 potential competition exclusions of evolutionary close species with similar niches. On the other

124 hand, communities composed of closely related species may indicate possible environmental 
125 filtering of species adapted to a similar environment (Webb et al. 2002). From this, the use of

126 phylogenetic information in conservation biology and community ecology became on occasion

127 indistinguishable, whereas the purposes of each domain highly differ in general. This resulted in

128 the absence of consideration of one of the main goals of the use of phylogenetic information in

129 conservation for many studies: the preservation of features' variations that may allow to maintain

130 future options for humanity (Faith 1992).

131 This review aims to reinforce the rationale for the use of phylogenetic metrics in

132 biodiversity conservation and their direct link with practical strategies while identifying some

133 limitations and areas requiring further development in the existing methods. A parallel will be

134 drawn with the use of phylogenetic information in community ecology to highlight how different

135 assumptions and objectives, which are discussed for both biodiversity conservation and

136 community ecology, may result in different uses of phylogenetic information. Finally, limitations

137 for those uses in both fields are discussed in detail and we highlight how they may be alleviated.

$139 *$ S1Basic Principles For the Use of PD in Conservation Biology

$141 \quad *$ T1The reason to use PD in conservation relies heavily on its link with feature diversity

142 (Faith 1992). Here we present the principles at the basis of this relationship and some of the

143 resulting implications for conservation biology. We focus on the main arguments that justify the

144 use of PD, although some others can be found elsewhere (e.g., Maclaurin and Sterelny 2008;

145 Tribot et al. 2016; Faith 2017Faith 2016b). The aim here is to guide readers to understand the

146 value of PD in regard to practical applications such as the ones proposed in the following

147 sections. We also referred to studies that have investigated the mechanisms at stake to explain the

148 relationships between phylogenetic and functional diversity in macro-organisms, but also in

149 micro-organisms (e.g., Goberna and Verdú 2016; Faith 2018a). 
151 *S2Phylogenetic Diversity and Feature Diversity: A Relationship Based on Evolutionary

152 Principles

153

154 *T1Darwin observed that "species of the same genus have usually, though by no means

155 invariably, some similarity in habits and constitution" (Darwin 1859:76). This observation has

156 been one of the main justifications behind the use of phylogenies in conservation biology, but is

157 also a matter of debate (Faith 2018a,b; Mazel et al. 2018). Many phylogenetic metrics used in

158 conservation were assumed to capture the variability or the scarcity of morphological or

159 functional traits (e.g., Faith 1992; Redding and Mooers 2006; Davies et al. 2016). This

160 assumption is inherent to Darwin's theory that introduced the principle of filiation with

161 modification in which shared characters can be explained by shared ancestry. This principle on

162 which PD (among other measures) relies, have several implications: first, closely related species

163 may share more characters than distantly related species; second, species descending from long

164 branches are more likely to capture more ancient characters than species descending from shorter

165 branches; and, third, summing the branch lengths that join species on a tree (a calculus from

166 which the set of PD-based indices originates) captures, on average, their feature variation. Yet,

167 some approaches missed this pattern-process model, which led to some misinterpretations (Kelly

168 et al. 2014).

169

$170 *$ S2Can Evolutionary History Reveal Future Benefits to Societies?

171

172 *T1Biodiversity provides multiple services to humanity (Gascon et al. 2015) that have

173 been classified under the notion of "ecosystem services." These services include regulation,

174 production, habitat, and information functions (Millennium Ecosystem Assessment 2005). Going 
175 further, Faith $(1992,1994)$ introduced the primary goal of PD for conservation: by measuring

176 feature diversity, PD maintains unanticipated and future benefits of biodiversity to human well-

177 being, i.e., option values. Although ecosystem services are useful at focusing on current rapidly

178 sensible benefits, option values consider long-term, human well-being that may depend on overall

179 and more complex biodiversity sets (Faith 2012). The concept of option values dates back to the

180 1970s: at this time it was already predicted that high rates of species extinction may cause the

181 loss of options to humanity (Iltis 1972; see Faith 2018a for a review). For Bishop, “[t]he loss of

182 any species irreversibly reduces the reservoir of future resources" (Bishop 1978:17) where

183 resources "are not, they become" (Bishop 1978:11), depending on human tastes, preferences, and

184 needs, among others. Bishop (1978) showed that resources are uncertain and may irreversibly be

185 lost with species extinctions. Today, preserving those unexpected future benefits appears crucial

186 in the face of the many threats accelerating species extinctions and population loss such as

187 climate change (Faith and Richards 2012). Indeed, it is almost given that uncertainties linked to

188 the consequences of biodiversity losses will always persist, but the best conservation decisions

189 have to be taken in spite of those uncertainties (Forest et al. 2015; Oliver 2016).

190 The unanticipated services of biodiversity may be provided by species evolutionary history

191 and potential and, thus, captured by a measure such as PD that may help to maximize a variety of

192 features on which future services depend (Mouillot et al. 2016). Biodiversity conservation

193 strategies based on PD are a "form of risk analysis that involves estimating patterns of variation,

194 and then trying to conserve as much of that estimated variation as possible — as a way to retain

195 'options' (possible values) for the future" (Faith and Baker 2006:121). A well-known example of

196 option values and PD was presented by Forest et al. (2007) who found through experimentation

197 that maximizing PD is the best way to conserve the medicinal and economic uses of the Cape

198 flora, whereas a strategy based on species richness alone was less efficient. Oka et al. (2019)

199 found that phylogenetic distant tree species in Japan tended to provide different provisioning, 
200 regulating, and cultural services and, therefore, it may be expected that PD could capture the

201 variation of these services. In a similar logic, Faith (2018a) highlighted the insurance value of PD

202 at the scale of ecosystems. The identification of species allowing for the preservation of

203 ecosystem resilience is uncertain, but PD may help to maintain a variety of features that may

204 permit ecosystem to respond to the disturbance. Another striking example is the emerging

205 positive contribution of PD to human health. Indeed, maintaining bacterial phylogenetic diversity

206 could have important consequences on the resilience of those bacterial communities and their

207 metabolic potential (Blaut and Clavel 2007; Lozupone et al. 2012; see also Faith 2018a for some

208 other examples). Although most of this review is built from studies on macro-organisms, PD has

209 also huge implications in the field of microbiology, especially because phenotypes of

210 microorganisms are largely unknown, but their variation may be predicted through phylogenetic

211 information (Goberna and Verdú 2016).

212 The potential surrogacy of PD for option values has encouraged its use for regional and

213 global conservation programs (Millennium Ecosystem Assessment 2005; IPBES 2018). In

214 particular, it may support the definition of a global measure of biodiversity based on a PD metric,

215 which would guide conservation efforts in the long term in the context of uncertainties regarding

216 environmental change (Faith 1992, 2016b; Forest et al. 2015). Indeed, conservation based on PD-

217 based measures should on average provide more goods to societies than those based on other

218 measures of biodiversity (Forest et al. 2007; Lean and Maclaurin 2016). Measures based on

219 phylogenies were also proposed as planetary boundaries in order to maintain a safe operating

220 system in which biodiversity benefits to societies would be preserved (Faith et al. 2010; Mace et

221 al. 2014). The rationale for using phylogenetic information as a planetary boundary is that it may

222 provide long-term ecological and evolutionary potential (but see below) and, as previously stated,

223 future benefits for societies. Last but not least, the Intergovernmental Science-Policy Platform on

224 Biodiversity and Ecosystem Services (IPBES) called to maintain the options provided by nature 
225 to humankind facing future needs (Díaz et al. 2015). From this, IPBES drew a framework based

226 on PD to estimate those "option values" and their threats (Faith et al. 2018; IPBES 2018). All of

227 these proposals based on "option values" make PD a powerful approach for conservation goals

228 that aim to maintain human well-being.

229 Although conserving PD may allow an increase in the probability that features providing

230 unexpected benefits to humankind are maintained, the relationship between PD and option values

231 would be even stronger if phylogenetic trees could reveal the evolutionary potential of species

232 (Mouquet et al. 2012). Indeed, this would help predict which set of species would best adapt or

233 diversify in the face of ecological changes and would be more likely to provide or preserve future

234 ecosystem functions and services (Sarrazin and Lecomte 2016).

236 *S2Do Phylogenetic Trees Reflect Opportunities For Future Evolution?

238 *T1Past and current human activities, besides species domestication, have imposed a

239 strong selection on species, their genetic diversity, and on their number (Hendry et al. 2011).

240 Estimating and preserving the possibilities for species to evolve, as a single unit and in

241 communities, appears crucial for the maintenance of biodiversity, especially in the face of

242 impending global environmental changes. Conserving species with high evolutionary potential

243 would contribute to maintaining biodiversity into the future and would help to preserve the

244 functions and associated services it provides to humans (Sarrazin and Lecomte 2016).

245 How can phylogenies help identify the evolutionary potential of species? First, using PD to

246 maximize feature variation would in principle increase the probability that feature diversity,

247 which is vital for species to be able to adapt to future environmental changes, will be maintained,

248 consequently providing evolutionary potential. This assumption has been introduced by Faith

249 who noted that PD ensures "that one or more members of the subset can adapt to changing 
250 conditions" (Faith 1992:2). Later, Forest et al. stated that features useful for the adaptation of

251 species to change are not known such that "maximizing PD will in turn maximize the options for

252 future diversification" (Forest et al. 2007:759). Yet, the relationship between PD and evolutionary

253 potential require further investigation.

254 Evolutionary history of species influences their phenotype and genotype, which then may

255 impact on the direction and speed of contemporary evolution (Hendry et al. 2011). In the absence

256 of specific selection pressures, species with a long history of evolutionary independence are more

257 likely to harbor unique genetic variation that, in turn, may allow them to adapt to change in

258 different ways from other species. Indeed, due to random mutations they may become either more

259 vulnerable or more resistant than other species (Hendry et al. 2011). In contrast, young lineages

260 may evolve more rapidly and have a greater capacity to diversify or adapt and could serve as the

261 source of long-term evolution (Hendry et al. 2011; Mouquet et al. 2012). However, whether long

262 or short branches best represent the possibilities of future evolution is still poorly understood and

263 further research on this topic is needed to guide conservation practices (Rolland et al. 2012).

264 Some authors suggested that estimating past diversification rates across current lineages might

265 indicate which lineages would be more prone to diversify in the future (Rolland et al. 2012). The

266 potential for future evolution of a species might also be assessed by combining information on

267 rates of trait evolution and diversification (Morlon et al. 2010). However, several researchers do

268 not support the idea of using phylogenies for estimating the future possibilities of evolution in

269 particular because empirical proofs are lacking, which paves the way for new research (Rolland et

270 al. 2012; Winter et al. 2013). Thus, in spite of some authors arguing that PD is related to

271 evolutionary potential (e.g., Voskamp et al. 2017), there are no stringent proofs, to our

272 knowledge, that it is actually the case.

273 
*T1Although the primary goal of using PD for conservation is the maintenance of feature

277 variation and "option values," some authors have been interested in the relationship between PD

278 and the diversity of some functional traits (e.g., Loreau et al. 2001; Hooper et al. 2005). Given

279 that phylogenetic variation may represent variation in species traits, based on the principle of

280 "filiation with modification," it has been argued that PD could be a good surrogate of functional

281 diversity (Faith called this the proxy value of PD; Faith 2018a) and capture ecosystem functions

282 (Srivastava et al. 2012; Davies et al. 2016). The main idea follows the community ecology

283 framework (Webb et al. 2002): communities with high mean phylogenetic distance among

284 species (i.e., communities composed of distantly related species) should comprise species with

285 high niche complementarity owing to the evolution of different traits, implying high niche

286 differentiation among distantly related species (Srivastava et al. 2012). Given this higher niche

287 difference, and consequently higher complementarity, the resources in the environment would be

288 more efficiently used, providing higher yields of given processes such as productivity in plants

289 (Srivastava et al. 2012).

290 Moreover, communities composed of distantly related species should have lower levels of

291 exploitative competition due to niche differentiation and, thus, would be more buffered against

292 competitive exclusions (Webb et al. 2002). Second, as phylogenetic difference may relate to

293 feature difference and ecological functions are generally provided by interrelated multiple traits, a

294 community of distantly related species may be functionally highly diverse, and this was shown to

295 increase the ecosystem functions provided (Cadotte 2015; Cadotte and Davies 2016). Contrary to

296 the rationale for the use of PD to conserve option values, the relationship between PD and

297 ecosystem functions is thus not based on the preservation of biodiversity units but rather on the

298 maintenance of ecological integrity (Faith 2018a). However, the relationship between PD, 
299 functional diversity, and ecosystem functions is not always well supported, a topic we discuss

300 further (see the section titled When Phylogenetic and Feature Variation Are Not Congruent:

301 Limitations and Solutions).

302 A conclusion that can be drawn from this section is that the surrogacy between PD and

303 feature diversity is well founded: it relies on basic evolutionary principles that tend to make

304 closely related species more similar in traits than distantly related ones. Many assumptions that

305 use PD in conservation depend on this relationship. The conservation logics presented here

306 comprises the proxy value (PD may reveal ecosystem processes), the option value (PD may

307 capture unexpected future benefits to humanity), and the insurance value (PD may preserve the

308 resilience of an ecosystem; Faith 2018a). The option value argument is certainly the best-

309 supported reason for the use of PD in conservation. Further, we will discuss appropriate

310 conservation practices that correctly consider the relationship between PD and feature diversity,

311 and others that fail to account for this surrogacy, leading to the loss of benefits linked to the use

312 of PD. In particular, we will emphasize approaches based on evolutionary distinctiveness that,

313 although they may not allow to maximize feature variation, have a high practical interest.

$315 *$ S1Practical Use of Phylogenetic Information in Conservation

$317 *$ S2Conserving PD and Feature Variation

$319 *$ *S3The PD Calculus

320

$321 \quad * \mathrm{~T} 1$ As stated above, the main benefits linked to the use of measures based on phylogenies

322 in conservation is to capture feature variations, which is beneficial to society faced with

323 unpredictable change and may help for the adaptation of biodiversity to change(Faith 1992).

324 Justified by the rationale that shared features are due to a shared ancestry, optimizing the 
325 conservation of feature variation may be achieved by securing the species that capture the highest

326 proportion of a phylogenetic tree. This aim is reached by maximizing the sum of branch lengths

327 of a phylogenetic tree that is protected, i.e., maximizing the PD calculus (the PD of a set of

328 species is equal to the sum of the lengths of all the branches from the corresponding minimum

329 spanning path; Faith 1992), whereas measures that preserve some branch lengths several times do

330 not maximize feature variation (Faith et al. 2004; Faith and Baker 2006). A direct consequence is

331 that in a scenario where only a limited number of species can be rescued, those capturing the most

332 PD should be prioritized. On the contrary many metrics based on phylogenetic trees may

333 not be suitable to achieve this goal (see for example “*T1Another strategy is to give priority

334 to the threatened diversity of a region. Several PD-based measures have been developed with this

335 specific aim in mind (e.g., Faith 2008; Rosauer et al. 2009). A crucial aspect to consider is that

336 the risk of losing a deep branch depends on the risk of losing all of the species it supports (i.e., the

337 phylogenetic complementarity of extinction risks). If this complementarity is not accounted for,

338 the risk of losing deep branches will be incorrectly assessed and, consequently, so is the risk of

339 losing PD (Steel et al. 2007; Faith 2008; Veron et al. 2016, 2017). Extinction risks are generally

340 based on probabilities of extinctions (Faith 2008) or on the restricted range of species (Rosauer et

341 al. 2009). Estimating PD on a phylogenetic tree where branches are weighted by those extinction

342 risks may represent how much feature diversity is threatened. In spatial planning, those measures

343 can be included in a PD gain strategy as described above. One would prioritize the sites that

344 would secure the maximum threatened PD of a region while considering its phylogenetic

345 complementarity (Veron et al. 2018). This may result in very different conservation strategies

346 than when extinction risks are not accounted for. Finally, information about land use, probability

347 of strategy success, or conservation costs could also be used together with a PD gain approach to

348 comply with the requisites for conservation planning assessments (e.g., Billionnet 2013). 
In conclusion, the approaches described above are not exhaustive and several strategies

350 may be adopted to conserve PD in spatial planning or in species prioritization strategies (other

351 measures are described by Faith 2008). However, assuming that shared traits are due to shared

352 ancestry, the rationale to preserve feature variation and potential option values should rely on the

353 phylogenetic complementarity of sites and/or species. This may help to clarify the use of PD in

354 conservation (Winter et al. 2013) and to consider the criteria of evolutionary history in the

355 implementation of practical conservation actions.

356 Figure 1. THREE PRIORITIZATION STRATEGIES BASED ON PD. PD is measured as the sum of

357 branch lengths on the spanning path joining taxa on a tree to the root. In all scenarios we assume

358 that only three sites out of four can be protected due to limited resources. Protected sites are

359 represented by red squares and safe branches are shown in black. 1) The conservation value of a

360 site is represented by its total PD. The first site to be chosen includes species $A, B$, and $D(P D=$

$36126 \mathrm{Ma}$ ). The second site selected comprises species A and B with PD = $20 \mathrm{Ma}$, although no

362 additional branch length is protected. Finally, the third site to protect harbors species C and D

$363(\mathrm{PD}=13 \mathrm{Ma}) .2)$ Sites are selected in function of their local PD gain: branch lengths are

364 weighted by the proportion of their range that is safe following the protection of a site. The order

365 of selection of sites is 1,4 , and 2. 3) Sites are prioritized following a global PD gain strategy: the

366 protection of one occurrence of a species conduct to the gain of all branches supporting that

367 species. Only two sites, those numbered 3 and 2, are needed to protect the entire tree.

*S2THE ED FRAMEWORK”). Going further, and by considering reasonable that

370 phylogenetic variation is a good surrogate of feature variation, PD, and PD-like measures

371 (e.g. Faith 1992; Faith 2008; Rosauer et al. 2009; Veron et al. 2017), are likely to be the

372 only existing measures based on phylogenetic trees that may help to preserve feature

373 diversity of conservation interest (Faith and Baker 2006; Faith et al. 2004). 
$376 *$ S3PD Gain

*T1Various measures have been proposed to extend the PD framework (Faith 2008). In

379 particular, we highlight here a method that allows the preservation of feature variation based on

380 PD gain (Faith 1992; Faith et al. 2018a). Phylogenetic diversity gain is defined as the amount of

381 branch length a species adds to the PD already represented by a given set of species, also known

382 as PD complementarity or PD endemism value, when the set of species is all other species (Faith

383 1992; Faith et al. 2004). In a conservation strategy, PD gain is the additional branch length that is

384 secured after the protection of species and/or sites. Consequently, PD gain is of great interest for

385 conservation planning because it helps to unravel how sites complement each other in order to

386 represent the overall diversity of a region. However, several regional studies have used the total

387 PD of a given site (often a grid cell) as its conservation value and thus did not consider that

388 branches can be shared among sites. This departure from the basic framework of conservation

389 planning based on the complementarity of sites (Margules and Pressey 2000) may originate from

390 the community ecology framework where the total PD of a site is of interest (e.g., Gómez-Ortiz et

391 al. 2017; see the section titled Why Approaches in Community Ecology and Conservation

392 Biology Should Be Different). Yet, in conservation biology, the purpose to maximize the

393 protection of a region's diversity is not achieved with this method because sites with the highest

394 total PD will most likely share branches and thus redundant information (Figure 1; Pollock et al.

395 2017; Faith et al. 2018a). This could lead to the prioritization of sites that add little branch length

396 (i.e., little PD gain) and, consequently, little feature diversity to a set of already protected sites.

397 Considering phylogenetic complementarity of sites and species is thus more appropriate to

398 capture feature variation. A recent set of works have incorporated PD gain as a strategy to protect 
399 biodiversity (e.g., Pollock et al. 2017; Rosauer et al. 2017; Veron et al. 2018). Interestingly,

400 Pollock et al. (2017) showed how PD gain could be used for conservation objectives at both

401 global and local scales. At global scale, securing one occurrence of a given species results in a

402 gain equivalent to the full length of the branches supporting that species (Figure 1). On the other

403 hand, when the aim is to emphasize local assemblages, the PD gained at a local site is measured

404 on a phylogenetic tree where each branch is weighted by the proportion of its protected range

405 (Figure 1; Pollock et al. 2007). Thus, a strategy to spatially protect PD would be to prioritize the

406 minimum number of sites that maximize the gain in PD (Figure 1; see also Faith et al. 2018 to

407 define an order of priority among these sites). Whether conservation objectives are local or global

408 may cause the identification of priority sites to differ (Figure 1).

409 One drawback of this PD gain approach is that it defines an effective set of protected sites yet, in

410 practice, protected areas are rarely implemented as a set. Thus, it remains essential to identify

411 sites that are likely to be important to include over many possible sets even though they do not

412 optimize the overall PD of a region. Those sites could be based on a hotspot approach as

413 proposed by Veron et al. (2018). Moreover, the PD gain approach for macro-organisms has

414 mainly been used at global or regional scales with the view of preserving "option values" (e.g.,

415 Mouillot et al. 2016). This approach could be extended at the scale of ecosystems where PD may

416 provide an "insurance value" (Faith 2018a). Species in the ecosystem that may be useful for its

417 resilience are unknown, but maximizing their PD and feature diversity may maximize its chance

418 to resist and/or recover from perturbations.

419

$420 \quad *$ S3PD At Risk

421

$422 \quad *$ T1Another strategy is to give priority to the threatened diversity of a region. Several PD423 based measures have been developed with this specific aim in mind (e.g., Faith 2008; Rosauer et 
424 al. 2009). A crucial aspect to consider is that the risk of losing a deep branch depends on the risk

425 of losing all of the species it supports (i.e., the phylogenetic complementarity of extinction risks).

426 If this complementarity is not accounted for, the risk of losing deep branches will be incorrectly

427 assessed and, consequently, so is the risk of losing PD (Steel et al. 2007; Faith 2008; Veron et al.

428 2016, 2017). Extinction risks are generally based on probabilities of extinctions (Faith 2008) or

429 on the restricted range of species (Rosauer et al. 2009). Estimating PD on a phylogenetic tree

430 where branches are weighted by those extinction risks may represent how much feature diversity

431 is threatened. In spatial planning, those measures can be included in a PD gain strategy as

432 described above. One would prioritize the sites that would secure the maximum threatened PD of

433 a region while considering its phylogenetic complementarity (Veron et al. 2018). This may result

434 in very different conservation strategies than when extinction risks are not accounted for. Finally,

435 information about land use, probability of strategy success, or conservation costs could also be

436 used together with a PD gain approach to comply with the requisites for conservation planning

437 assessments (e.g., Billionnet 2013).

438 In conclusion, the approaches described above are not exhaustive and several strategies

439 may be adopted to conserve PD in spatial planning or in species prioritization strategies (other

440 measures are described by Faith 2008). However, assuming that shared traits are due to shared

441 ancestry, the rationale to preserve feature variation and potential option values should rely on the

442 phylogenetic complementarity of sites and/or species. This may help to clarify the use of PD in

443 conservation (Winter et al. 2013) and to consider the criteria of evolutionary history in the

444 implementation of practical conservation actions.

445 Figure 1. ThreE PrIORITIZATION STRATEGIES BASED ON PD. PD is measured as the sum of

446 branch lengths on the spanning path joining taxa on a tree to the root. In all scenarios we assume

447 that only three sites out of four can be protected due to limited resources. Protected sites are

448 represented by red squares and safe branches are shown in black. 1) The conservation value of a 
449 site is represented by its total PD. The first site to be chosen includes species $\mathrm{A}, \mathrm{B}$, and $\mathrm{D}(\mathrm{PD}=$

$45026 \mathrm{Ma}$ ). The second site selected comprises species A and B with PD $=20 \mathrm{Ma}$, although no

451 additional branch length is protected. Finally, the third site to protect harbors species C and D

452 (PD = $13 \mathrm{Ma})$. 2) Sites are selected in function of their local PD gain: branch lengths are

453 weighted by the proportion of their range that is safe following the protection of a site. The order

454 of selection of sites is 1,4 , and 2. 3) Sites are prioritized following a global PD gain strategy: the

455 protection of one occurrence of a species conduct to the gain of all branches supporting that

456 species. Only two sites, those numbered 3 and 2, are needed to protect the entire tree.

$458 *$ S2The ED Framework

$460 *$ S3Evolutionary Distinctiveness Does Not Allow the Protection of Feature Variation

463 trees that has been widely used in conservation biology. It quantifies the number of relatives a

464 species has, how phylogenetically distant they are, and assigns an individual score to each species

465 in the phylogenetic tree. For example, the widely used fair proportion index partitions the branch

466 lengths of a phylogenetic tree (i.e., PD) among all of the species it supports (Isaac et al. 2007).

467 Species are then prioritized according to their ED value. This also implies that the sum of all ED

468 scores measured on a phylogeny is equal to the total PD of all taxa comprised in this tree.

469 The ED order of prioritization is, however, not as efficient as the PD calculus at capturing

470 the variations of features (Figure 2). This is mainly because ED measures do not account for the

471 phylogenetic complementarity among species (i.e., by conserving species with the highest ED,

472 some deep branches are likely to be represented several times whereas others may not be

473 represented at all; Figure 2). Feature variation is therefore not properly captured. For example,

474 Isaac et al. (2007) argued that the species with the highest ED scores, and thus the highest 
475 priority, would be two closely related species. However, the choice of those two species does not

476 look to be the best strategy to maximize feature variation as it does not represent the highest

477 protected proportion of the tree of life (see the section titled *S2Conserving PD and Feature

478 VARIATION). In a PD-based strategy, two distantly related species would have been selected to

479 protect most feature variation.

480 Similarly, some spatial planning research has focused on preserving sites with the highest

481 ED values, especially by summing/averaging ED scores of the species occurring in each site and

482 prioritizing sites with the highest cumulative ED (e.g., Daru et al. 2013; Safi et al. 2013; Jetz et al.

483 2014). This method should also not be viewed as a conservation planning strategy that maximizes

484 feature variation because phylogenetic complementarity is not taken into consideration. These

485 arguments related to spatial planning can be applied to all types of ED measures even those that

486 include extinction risks or endemicity such as Evolutionary Distinctiveness and Global

487 Endangerment (EDGE; Isaac et al. 2007), Heightened Evolutionary Distinctiveness and Global

488 Endangerment (HEDGE; Steel et al. 2007), Biogeographical weighted Evolutionary

489 Distinctiveness (Cadotte and Davies 2010), Loss-significant Evolutionary Distinctive Globally

490 Enduring (LEDGE; Faith 2015), or After Downlisting Expected Phylogenetic Diversity (ADEPD;

491 Nunes et al. 2015).

492

493 *S3Evolutionary Distinctiveness Remains a Useful Measure For Practical Conservation

494

495 *T1Although an approach based on preserving species with high ED may not be the best

496 strategy to capture feature variation, this measure is still valuable for conservation biology. First,

497 the rationale of protecting species with high ED values is linked to their isolation from all other

498 species and to the fact that they may represent long branches capturing old features shared by

499 very few species (Magnuson-Ford et al. 2009; Redding et al. 2010; Collen et al. 2011; Stein et al. 
500 2018; but see Grandcolas and Trewick 2016). From this, conservation of species with a high ED

501 generally would be able to capture a lot of PD (although it is not the maximum PD) and would

502 contribute to the maintenance (but not the maximization) of feature variation (Faith et al. 2018).

503 Other arguments to preserve highly evolutionary distinct species are essentially practical

504 (e.g., Faith 2015; Forest et al. 2018; Stein et al. 2018; Thévenin et al. 2018). Isaac et al. justified

505 the protection of species with the highest ED values, despite the fact that they are closely related,

506 because "the extinction of either would leave a single descendant of the oldest and most unusual

507 lineage in the phylogeny” (Isaac et al. 2007:2). For Redding and Mooers (2006), real-world

508 conservation practice is based on lists of threatened species, and PD does not offer an order of

509 conservation prioritization, especially because there will be as many possible rankings of species

510 as there are PD maximizing solutions in a set of species. A species list based on PD may be

511 difficult to implement at the management level (Redding and Mooers 2006). Moreover, strategies

512 based on maximizing PD are based on a set of species (or sites). Consequently, the conservation

513 of a species outside this set may lead to the identification of a new and very distinct set to

514 preserve PD, and management actions are rarely implemented on a set of species or sites (e.g.,

515 Thévenin et al. 2018). Thus, it remains important to identify species that may capture large

516 amounts of PD independently of a given set. To this aim, because they may be evolutionarily

517 isolated and descending from long branches, species with high ED may capture more branch

518 lengths and more PD than species with low ED as showed by Redding et al. (2008).

519 Regarding extinctions, Chaudhary et al. (2018) showed that summing the ED scores of

520 extinct species was strongly correlated to PD loss. By looking at the calculus of ED and expected

521 loss of PD, Faith et al. (2018) showed that the sum of ED scores of threatened species was

522 approximately the total expected loss of $\mathrm{PD}$, assuming that the probabilities of extinctions of

523 threatened species were close to 1. 
524 To summarize, the ED approach has many advantages, but future research based on this

525 measure should be aware that it does not maximize feature variation and option values. High ED

526 species may capture rare features and have practical interest to capture more PD than expected

527 when the protection of a set of species maximizing PD cannot be set up in real-world

528 conservation actions.

529 Figure 2: Comparison of PD and ED in maximizing feature variationThis figure represents the

530 selection of species based on A) evolutionary distinctiveness (estimated here through the fair

531 proportion index) and B) the PD value. Developing a conservation strategy based on ED does not

532 maximize feature variation. Marks on branches represent the unique features it captures based on

533 the simplified assumption that the number of unique features is proportional to branch length. In

534 A, species E and F are prioritized due to their high ED scores. This represents $15 \mathrm{Ma}$ of branch

535 length and 15 unique features. In B, species B and F (or E), which maximize PD, are selected,

536 and they capture $20 \mathrm{Ma}$ of PD and 20 unique features.

537 The rationale to preserve feature variation and related conservation benefits may be

538 reached by a PD calculus that maximizes the proportion of the Tree of Life protected. However,

539 some PD approaches were erroneously thought to protect feature variation whereas they may be

540 more informative in the field of community ecology. In the next section we will underline what

541 these approaches are and how different goals in conservation biology and community ecology

542 require different uses of PD.

543

$544 *$ S1Why Approaches in Community Ecology and Conservation Biology Should Be Different 545

546 *T1Some approaches using PD in conservation biology have likely been influenced by 547 those applied in community ecology (or at least they became similar on occasions) resulting in 548 wrong interpretations and practices. Although we previously discussed what phylogenies can tell 
549 us about feature variation and its potential for conservation, in this section we discuss what PD

550 can tell us about species interactions influencing community and network assembly. By doing so

551 we will show why and when approaches in conservation biology and community ecology should 552 differ.

553

$554 *$ S2Some Phylogenetic Information of Interest in Community Ecology: Niche Conservatism and 555 Community Assembly

556

*T1As previously mentioned, the idea that phylogenetic distance should be related to

558 species interaction can be traced back to Darwin (1859). He hypothesized that, because of their

559 common ancestry, congeners should have many similar characters, increasing the chances of

560 exploiting the environment in a similar fashion — what would be later known as the competition-

561 relatedness hypothesis (Cahill et al. 2008). Gause (1934), inspired by Darwin's ideas and by

562 Lotka (1925) and Volterra (1926), established the foundations for the theory of competitive

563 exclusion. This theory proposes that two species occupying the same ecological niche cannot

564 coexist in a stable manner. It was later complemented by the limiting similarity model—

565 introduced by MacArthur and Levins (1967) and revised by Abrams (1983) — that demonstrates

566 mathematically how species coexistence could be limited by their degree of niche overlap. Works

567 by Felsenstein (1985) and Harvey and Pagel (1991) introduced the first formal discussions

568 surrounding the concept of niche conservatism. Because a species is expected to not easily adapt

569 to conditions outside its fundamental niche, evolutionary changes are likely to be an inherently

570 conservative process (Holt and Gaines 1992; Wiens and Graham 2005). Thus, closely related

571 species should fundamentally overlap in their niches.

572 Based on the concepts of niche conservatism and limiting similarity, Webb et al. (2002)

573 proposed the use of phylogenetic relatedness as a surrogate for niche overlap, which allowed for 
574 the understanding of community assembly through the analysis of patterns of phylogenetic

575 structure. According to their logic, when closely related species co-occur more often than

576 expected by chance (i.e., phylogenetic clustering), one could infer the predominance of

577 environmental filtering, whereas when closely related species co-occur less than expected by

578 chance (i.e., phylogenetic overdispersion), one could infer the predominance of competitive

579 exclusion due to the limited similarity among closely related species. This concept has been

580 widely used due to the straightforward way that observed patterns can be interpreted and the

581 increasing availability of comprehensive data sets (Cavender-Bares et al. 2004; Vamosi and

582 Vamosi 2007; Emerson and Gillespie 2008).

583 Although environmental filtering and competitive exclusion are only a part of the story

584 explaining how species could coexist (Gerhold et al. 2015; Saito et al. 2018), these assumptions

585 foster the use of PD in community ecology that, therefore, relies on very different logic than in

586 conservation biology.

587

$588 *$ S2Phylogenetic Diversity in Community Ecology—A Generalization

$590 \quad *$ T1From the logic described above, several metrics based on phylogenetic trees have been

591 developed in community ecology that are related to divergence, diversity, and evenness (Tucker

592 et al. 2017). We will here focus on the use of PD to show how it differs from its use in

593 conservation biology; reviews on other measures are available elsewhere (e.g., Pavoine and

594 Bonsall 2011; Tucker et al. 2017).

595 The PD value (Faith 1992) of a set of species found at a given site has been employed as a

596 measure of phylogenetic alpha diversity (e.g., Chai et al. 2016) to assess the coexistence or

597 functional differences among species (Cadotte et al. 2010). One particular approach has been to

598 compare the PD and species richness (SR) at a given site. High PD compared to SR would relate 
599 to the occurrence of distantly related species and indicate potential competitive exclusions, while

600 low PD over SR may reveal communities composed of closely related species and possible

601 environmental filtering (overdispersion versus clustering; see above). For example, Chai et al.

602 (2016) used this approach to reveal the deterministic and stochastic process at the origin of

603 diversity patterns in a long-term study of forest succession. Moreover, relative PD might provide

604 insights into evolutionary processes, including the balance between speciation and extinction that

605 affect community assembly (Pavoine and Bonsall 2011). Davies and Buckley (2011) measured

606 the mammal relative PD in individual sites to disentangle areas where speciation has been rapid

607 and immigration rare (low PD relative to species richness) and areas where diversification has

608 been slow and long-distance immigrations frequent (high PD relative to species richness).

609 This is, of course, a very general view of the use of PD in community ecology that is often

610 employed in combination with other measures (Cadotte et al. 2010; Pavoine et al. 2013).

611 However, this shows that PD is used for different purposes in community ecology and

612 conservation biology and should not be confused. Although the PD of a given site may be of

613 interest to understand community assembly, it may be less important in conservation biology

614 where, to preserve feature variation, the phylogenetic complementarity of sites and species is

615 considered. There are cases when community ecology and conservation ecology meet, for

616 example, to predict the effect of invasions (Yguel et al. 2011, 2014) or ecosystem functioning, as

617 discussed above. Yet, we prefer to highlight the main differences and avoid sources of confusion

618 in both fields of ecology.

619

$620 *$ S1When Phylogenetic and Feature Variation Are Not Congruent: Limitations and Solutions

621

622

*T1A common point in conservation biology and community ecology frameworks is the

623 use of PD under the assumption that large evolutionary distances among species indicate more 
624 feature differences among them. All of the benefits that can result from this relationship make it

625 likely that many studies based on PD will be conducted in the future. Yet, existing limitations and

626 misinterpretations to this assumption have fuelled the ongoing debate on the use of phylogenetic

627 information in both conservation biology and community ecology (e.g., Cadotte et al. 2017;

628 Mazel et al. 2018). As stated by Faith and from what is clear in the original PD paper (Faith

629 1992) "PD should not be expected to magically make inferences about every favorite character or

630 feature" (Faith 2018a:6). This implies that, despite clear benefits, some conclusions from PD

631 investigations should be drawn with care. We present some of the most common sources of

632 limitations in the PD and feature diversity relationship, their consequences, and how they may be

633 alleviated. Some limitations have also been treated in depth by other authors, so the general

634 overview we present here may be complementary to previous work (e.g., Cadotte et al. 2017; Box

635 1). We focus our attention on how these limitations may (or may not) weaken the conclusions

636 drawn from PD analyses in conservation and community ecology presented in the section above.

$638 *$ S2A General Overview of Existing Limitations

639

$640 *$ S3Phylogenetic Reconstruction

641

$642 \quad *$ T1Modern phylogenetic trees originated from cladistics, a set of methods used to

643 reconstruct relationships between organisms established by Hennig (Hennig 1950, 1965).

644 Phylogenetic trees enable the grouping of species/organisms based on the analysis of homologous

645 characters (i.e., characters inherited from a common ancestor). Currently, this method is the

646 preferred principle to classify organisms and numerous statistical and computational tools have

647 been developed (Box 1; e.g., maximum parsimony, maximum likelihood, and Bayesian methods)

648 in the quest to find the most accurate phylogenetic trees (Huelsenbeck et al. 2001; Tamura et al.

649 2011). 
All of the tools available for phylogenetic tree reconstruction have advantages, drawbacks,

651 and limitations that should be carefully considered. In Box 1 we relate sources of uncertainties in

652 some of the most employed methods for phylogenetic reconstruction. This shows that the

653 relationship between phylogenetic variation and feature variation may already be blurred by these

654 reconstruction methods.

655

Box 1

Phylogenetic tree reconstruction methods as source of uncertainties

659 that guarantees the recovery of the "true" tree. Methods for inferring phylogenetic trees are

660 classified into two categories according to the type of data used: distance-based and character-

661 based.

662

*S1Distance-Based Methods

*T1Distance matrix methods start by converting molecular data into a pairwise distance

666 matrix, which is then used for inferring a phylogenetic tree. There are mathematical models to

667 calculate distances between each pair of operational taxonomic units (OTUs), based on different

668 models of molecular evolution that result in different genetic or evolutionary distances. Most

669 distance methods use clustering algorithms to construct a single phylogenetic tree. These methods

670 are suitable for the rapid analysis of large datasets as they are not computationally demanding. 
*T1UPGMA is one of the simplest methods for tree reconstruction. The clustering works by

675 searching for the smallest pairwise distance value between OTUs in the matrix that will form a

676 new cluster. Then a new distance matrix is calculated between the newly formed cluster and the

677 remaining OTUs. The process continues until all OTUs are clustered. The tree is formerly

678 additive and thus all nodes are equally distant from the root. UPGMA assumes that evolutionary

679 rates in all branches are similar, which is generally not the case (Nei 1991).

*S2Neighbor Joining (NJ)

*T1This method differs from UPGMA in that there is no assumption about the distance

684 between OTUs. The NJ algorithm does not construct clusters, but minimizes the length of all

685 internal branches (Saitou and Nei 1987). The process begins with an estimation of evolutionary

686 distances correcting for multiple substitution events at the same site. In a second step, the

687 minimal distance is used to introduce a new node that groups a pair of OTUs for which

688 evolutionary distance is minimal. Then a new matrix is calculated from the new node to each

689 other's terminal node. The process is repeated until an unrooted tree is constructed. A distantly

690 related taxon (outgroup) can be chosen to root the tree.

692 A serious weakness for distance methods such as NJ and UPGMA is that the observed differences

693 between sequences are not accurate reflections of the evolutionary distances between them,

694 especially due to non-constant evolutionary rates. In that case, corrections must be applied, but

695 there is no consensus on what correction could be the best. NJ and UPGMA appear as suitable

696 methods when sequences have diverged recently, but could be particularly misleading when

697 estimating old relationships (Holder and Lewis 2003). Other distance-based methods are Fitch-

698 Margoliash, minimum evolution, or least-squares algorithms. 
*T1Character-state methods use variation in a set of discrete characters (e.g., sequence data) to construct phylogenetic trees. In contrast to distance-matrix methods, they can be used to

704 reconstruct ancestral character states because they retain the original character status of the taxa.

*S2Maximum Parsimony (MP)

$708 *$ T1Under the maximum parsimony criterion, the best tree is one that requires the minimum

709 number of character changes (e.g., nucleotide substitutions) to produce the data (e.g., a set of

710 homologous sequences). However, there are many plausible scenarios that could have produced a

711 group of sequences and considering a single mutational path, as MP does, may be misleading

712 (Holder and Lewis 2003). MP assumes that common characteristics are inherited from a common

713 ancestor, but when homoplasy (parallelisms, convergences, and reversal events) is present, the

714 most parsimonious method may underestimate the actual evolutionary divergences. The MP

715 algorithm usually finds more than one tree with the same parsimonious length. A consensus

716 approach is then built up to combine all of the most parsimonious trees. The MP method does not

717 consider the fact that the number of character changes may vary on each branch of the tree. Long-

718 branch attraction occurs when rapidly evolving taxa are placed together on a tree because they

719 have many mutations (Rizzo and Rouchka 2007). Yet, parsimony performs relatively well if the

720 amount of convergence is rare compared with the number of mutations that are conveying useful

721 information (Holder and Lewis 2003). There are other different parsimony algorithms such as

722 weighted, transversion, or Dollo parsimony. 
*T1This method allows for the correction of multiple mutational events at the same location.

727 Likelihood methods measure the probability of the data given the hypothesis (i.e., it prefers the

728 tree with the highest probability to fit the observed sequences). ML optimizes the likelihood of

729 observing data given a tree topology and a model of nucleotide evolution (Egan and Crandall

730 2006). ML assumes a model of evolution and the tree returning the highest likelihood is

731 considered the best tree. An advantage of ML is that it accounts for the possibility of unseen

732 events such as back mutations or complex pathways (Holder and Lewis 2003). As for MP, it

733 examines different tree topologies. This method is very robust for reconstructing old relationships

734 and fast evolutionary events, but is one of the most computationally demanding and may be

735 inappropriate for relatively large data sets. To tackle those computer load issues, more recent

736 methods based on ML have been developed, in particular PhyML (Guindon et al. 2010), RAxML

737 (Stamatakis 2006), and IQ-TREE (Nguyen et al. 2014), among others.

All of the methods described above require a form of confidence assessment for the

740 relationships inferred in the tree. The most common tool to establish this confidence is called

741 "bootstrapping," which consists of creating pseudo-replicate data matrices by randomly

742 resampling the original data set (with replacement) and reconstructing phylogenetic trees for each

743 (Lemey et al. 2009). Bootstrap values provide a measure of support for the monophyly of clades

744 and the relationships among studied taxa.

$746 *$ *S2Bayesian Methods 
*T1Bayesian methods simultaneously estimate trees and measures of support for every

749 branch. This approach searches for a set of trees representing the data by using a prior probability

750 for the distribution of each parameter of the model (or equal probabilities if we do not have prior

751 information). The optimal tree is the one that maximizes the posterior probability that is

752 proportional to the likelihood multiplied by the prior probability. The posterior probabilities

753 specify the probability of each tree given a model, a prior, and the data. A technique called

754 Markov chain Monte Carlo (MCMC) is used to explore tree space. An advantage of Bayesian

755 techniques is that they allow the implementation of complex models of sequence evolution.

756 Moreover, contrary to ML, Bayesian approaches may be reliable even when the ratio of data

757 points over the number of parameters is low. Unfortunately, Bayesian methods are very

758 computationally demanding and selecting an uninformative prior may result in serious issues.

$760 *$ S3Different Rates of Feature Evolution and Convergences Can Blur Phylogenetic Signals

*T1Evolutionary rate variation among features may influence how similar closely related

763 species are in a phylogenetic tree. Fast evolving features may tend to be very different between

764 closely related species and reveal little about evolutionary history (Losos 2011). Phylogenetic

765 signals in features can thus be revealed only when the rates of character evolution are low relative

766 to rates of clade evolution (Losos 2011).

767 Another reason why phylogenetic similarity may not reflect feature similarity is because of

768 convergent evolution (Faith 1992). This is the process by which evolutionarily unrelated

769 organisms show similar features as a result of natural selection and adaptation. Because of

770 convergences, several features in different clades do not show any phylogenetic signal (Mazel et

771 al. 2017). As stated by Faith (1992), the PD index does not capture convergent features because

772 they depart from the assumption that shared traits are due to a common evolutionary history. 
773 Although this principle is inherent in the evolutionary model on which PD is based, it has been

774 missed in some studies (e.g., Kelly et al. 2014). Therefore, convergent features should be

775 considered through other metrics, such as shared habitats as suggested by Faith and Walker

776 (1996).

777

$778 *$ S3Species Descending From Long Branches Do Not Always Retain Old Features

779

$780 \quad * \mathrm{~T} 1$ Species descending from deep nodes do not always exhibit features older than species

781 found in shallower nodes (Grandcolas and Trewick 2016). There are two potential reasons for this

782 situation. First, all characters of a species that have been in an evolutionary stasis are not in a

783 primary state. Grandcolas and Trewick (2016) showed that species found on long branches may

784 also have features considered more modern. Second, isolated species on long branches can be

785 remnants from a lineage formerly much more diverse that was decimated by subsequent

786 extinction events. Thus, the species that are remnants from an ancient group previously

787 comprising more species represent a combination of features of this group, but not always the

788 character states present in its ancestor (Grandcolas et al. 2014; Grandcolas and Trewick 2016).

789 The conservation interest of evolutionary distinct species and long branches, capturing large

790 amounts of PD, may not always rely on their unique features and possible related functions in an

791 ecosystem, but also to their level of endangerment and symbolic value (Isaac et al. 2007;

792 Grandcolas and Trewick 2016; Trewick and Morgan-Richards 2016).

793

$794 *$ S3Uncertainties Due to the Model of Feature Evolution

795

796 *T1The expectation that greater evolutionary distances indicate that species have

797 accumulated more ecological differences assumes a very particular evolutionary model (i.e., the

798 Brownian motion model). Phylogenies are often built following a Brownian motion model 
799 (Diniz-Filho et al. 2013). This model assumes that features continue to diverge linearly over time

800 and that convergence is rare. This supports the rationale to use PD in conservation and

801 community ecology (i.e., that shared features may be explained by shared ancestry; Cadotte et al.

802 2017). Cadotte et al. (2017) showed that under the Brownian motion model the relationship

803 between ecological and phylogenetic distance was linear only when multiple features (or

804 ecological traits) were considered, whereas this was not true for a single feature. PD may be a

805 good surrogate for variation of multiple features, but this surrogacy may weaken when the

806 number of features decrease (Diniz-Filho et al. 2013; Cadotte et al. 2017; Tucker et al. 2018), as

807 stated in the original paper introducing PD (Faith 1992). Yet, evolutionary, physiological, or

808 ecological constraints tend to make evolution models more complex than a Brownian motion

809 model. Many studies show that only a small proportion of features (or ecological traits) followed

810 a linear model of evolution and a model of bounded evolution was generally favored (Davies

811 2015). From this, the relationship between phylogenetic distance and ecological distance and

812 between the sum of branch lengths joining species and their feature variation can take many

813 forms (Cadotte et al. 2017; Tucker et al. 2018). For example, if evolution slows down over time,

814 phylogenetic diversity may capture little feature variation, whereas if evolution occurs in bursts,

815 much feature variation may be captured (Davies 2015). A useful review of the issues related to

816 the model of evolution can be found in Cadotte et al. (2017), and some practical solutions have

817 been proposed by Pagel (1999), Diniz-Filho et al. (2012), Letten and Cornwell (2015), Davies

818 (2015), and Mazel et al. (2016).

819 Yet, despite numerous possible evolutionary models, if "large numbers of species [are

820 examined] and combine multiple traits, which have been subject to different selection regimes,

821 then the pattern of evolution is likely to be indistinguishable from BM [Brownian motion model]"

822 (Cadotte et al. 2017:537-538). When this condition is met, PD may then still be a good predictor 
823 of feature (or ecological traits) diversity, independent of the evolutionary model of features

824 (Cadotte et al. 2017).

825

$826 *$ S2Consequences For the Use of Phylogenetic Information in Conservation Biology...

827

828 *T1One main benefit for the preservation of PD highlighted in this review is its

829 relationship with ecosystem processes and option values (Kraft et al. 2007). Up until now, some

830 studies have found that ecosystem processes were related to species richness, with a small

831 fraction of increase due purely to higher phylogenetic diversity (Venail et al. 2015; but see

832 Cadotte 2015). From the discussion above, it is clear that there are many reasons why

833 phylogenetic diversity itself may not be able to forecast functional diversity or the value of

834 ecosystem services (Venail et al. 2015). First, traits that control ecological functions are not

835 phylogenetically conserved, so that maximizing PD may not maximize feature variation.

836 Moreover, this implies that closely related species do not have similar ecological functions and

837 distantly related species do not complement each other's function. Second, closely related species

838 do not compete more strongly than distantly related ones, given all of the reasons discussed above

839 (see Mayfield and Levine 2010). Thus, communities composed by distantly related species do not

840 have more niche complementarity and better productivity than communities formed by closely

841 related species. Third, closely related species commonly experience facilitative interactions

842 (Cianciaruso et al. 2009). Thus, communities composed by closely related species can have

843 higher productivity when these species facilitate each other, in comparison with communities of

844 distantly related species that face competitive interactions. In spite of all these possible imitations,

845 PD was shown to be a strong predictor of ecosystem functioning (Cadotte 2015). This is likely

846 because by summing the phylogenetic distances of species in a community, PD represents the

847 variation (and not the difference) in species traits (i.e., the total niche space occupied; Cadotte et 
848 al. 2017). Moreover, when the additional benefits of using PD over other measures to capture

849 ecosystem processes are not clear, phylogenetic information may still be valuable (Cadotte 2015).

850 For instance, Yguel et al. (2016) argued that, even if PD remained useful for predictions related to

851 ecosystem processes, it may be too simple to depict differences in the phylogenetic structure of

852 communities. These authors then proposed a measure called Evolutionary Legacy of

853 Diversification, which describes branching patterns and may better predict ecosystem processes

854 than other commonly used metrics such as PD. Besides, ecological functions may not always be

855 provided by feature diversity but rather by key innovations (Davies et al. 2016). In that case

856 phylogenetic placement, for example, measured by metrics that describe the connectedness or

857 centrality of nodes and edges within a network, may better represent those functions than PD does

858 (Davies et al. 2016).

859 In addition, many studies showed that PD was not a good proxy for functional diversity

860 and that spatial patterns were incongruent most of the time (Devictor et al. 2010; Pavoine et al.

861 2013; Pollock et al. 2017; Cadotte and Tucker 2018; Mazel et al. 2018). Again, these results were

862 expected because only a few traits were considered, convergence may occur or models were not

863 convenient (see discussion in Faith 2018b). Appropriate measures to estimate functional diversity

864 and spatial priorities, which separately consider functional and phylogenetic diversity, are

865 therefore necessary (e.g., Cadotte and Tucker 2018).

866 Although some limitations and improvements can be found regarding the relationship

867 between PD and ecosystem processes and that some features do not show any phylogenetic

868 signals (Faith 1992), PD remains an important calculus to maintain option and insurance values.

869 PD may on average capture feature diversity that may be the best way to maintain unexpected

870 benefits to humanity and for the resilience of ecosystems. As shown above, this relationship does

871 not rely on only a few existing traits, but on the overall features of species with unknown

872 variation and unknown future values. Analyses based on a few traits have sometimes led to the 
873 wrong interpretation that PD does not capture option values (Faith 2018b). On the contrary,

874 "option values" is the primary argument for the use of PD calculus in conservation such that

875 "maximizing the retention of phylogenetic diversity (PD) should also maximize option value"

876 (Larsen et al. 2012).

877 In conclusion, despite the fact that niche conservatism provides the foundation for the PD

878 ecosystem services agenda, it has some limitations that should be acknowledged. Although PD

879 has been shown to be a strong predictor of ecosystem functioning, the key to understanding the

880 processes that explain this prediction is to go deeper into the phylogenetic signature of species

881 interactions that may result in the definition of new metrics based on phylogenies. Studies

882 investigating the relationship of PD and ecosystem functions and services will be more fruitful if

883 we acknowledge the underlying premises of phylogenetic signals and niche complementarity,

884 otherwise studies will have strong contingency and with low generalization for conservation

885 purposes.

886

$887 *$ S2... and in Community Ecology

888

*T1From the limitations described above (see the section titled *S1When Phylogenetic and

890 Feature Variation Are Not Congruent: Limitations and SOLUTIONS), assuming that niche

891 conservatism indicates the maintenance of the fundamental niche over time a priori and to link it

892 directly to competition between closely related species may sometimes be flawed (Kraft et al.

893 2007). Although many features are more conserved through evolutionary history than expected,

894 in cases of convergent or divergent evolution, the interpretation of phylogenetic patterns in the

895 face of assembly processes becomes confused (Losos 2008, 2011). For example, species from

896 distinct lineages where trait evolution is predominantly convergent can be assembled in

897 communities driven by environmental filters and yet their phylogenetic pattern can be 
898 overdispersed. In this case, if we assume niche conservatism, phylogenetic patterns, such as the

899 relationship between PD and SR, would be erroneously interpreted as competition between

900 closely related species. Moreover, when species are assembled by asymmetric competition —i.e.,

901 species have different competitive abilities — communities can have phylogenetically clustered

902 structures due to the competitive exclusion of distantly related species with inferior competitive

903 abilities (Mayfield and Levine 2010; Gerhold et al. 2015; Saito et al. 2016, 2018). From this,

904 relationships between phylogenetic overdispersion/clustering and competition/environmental

905 filtering is also not uniform across clades (Pearse et al. 2018). Cadotte et al. (2017) provides a

906 review on how to interpret the lack of phylogenetic signals in community assembly. Other points

907 for the weakness and strengths of inferring assembly processes from phylogenetic information,

908 such as understanding how coexistence leads to the macroevolutionary diversification of habitat

909 lineage pools or, on the contrary, how macroevolutionary contingency of habitat lineage pools

910 affects present-day species coexistence (Gerhold et al. 2015) were explored by others (Mayfield

911 and Levine 2010; Mason and Pavoine 2013; Gerhold et al. 2015; de Bello et al. 2017).

912 The use of PD in conservation biology and community ecology relies on a strong

913 theoretical background. Limitations exist that may blur or nullify the relationship between

914 phylogenetic variation and variation in some traits (e.g., Cadotte and Tucker 2018), potentially

915 influencing the conclusions that can be drawn from PD approaches. In particular, this may

916 influence the predictions of species interactions so that niche complementarity, species

917 assemblage, and ecosystem functioning can sometimes be difficult to interpret through PD. As

918 stated above, this situation could be improved by a clearer understanding of the phylogenetic

919 signature of species interactions. Finally, the relationship between genotypes and phenotypes and

920 how it affects the use of PD has received, to our knowledge, nearly no attention. Still, the

921 limitations regarding the use of PD in conservation and community ecology are better understood

922 (e.g., Cadotte et al. 2017) and incorrect interpretations occasionally arise from unfit analyses or 
923 inaccurate understanding of the rationale of PD usage (e.g., Kelly et al. 2014; Venail et al. 2015).

924 Several corrections, but also additional applications, have been proposed (e.g., Cadotte 2015;

925 Gerhold et al. 2015; Yguel et al. 2016). Although conclusions about the use of PD should

926 sometimes be mitigated, we believe that such improvements and good practices will allow the

927 appropriate use of phylogenetic information as a powerful tool for the future of conservation

928 biology and community ecology.

929

$930 *$ S1Conclusions

$931 * \mathrm{~T} 2$

932 1. The use of phylogenetic information in conservation biology and community ecology

933 relies highly on the assumption that shared features are due to a shared evolutionary

934 history.

935 2. Up until now, confusion between the conservation biology and community ecology

936 frameworks may have resulted to a misuse of phylogenetic information in many cases.

937 3. In conservation biology, the interest is to maintain option values through feature

938 variation. Strategies that do not consider the phylogenetic complementarity of sites and

939 species do not allow maximizing the chances to preserve option values, but some may

$940 \quad$ have a practical interest.

941 4. In community ecology, phylogenetic information may help to disentangle the process at

942 the origin of diversity patterns and community assembly in a given area, but phylogenetic

943 complementarity among sites is not always essential.

944 5. Yet, it should be noted that limitations in the relationship between features and

945 evolutionary history may lead to misunderstandings and misinterpretations in both

946 conservation biology and community ecology. 
6. Understanding and considering the conditions to use phylogenies for conservation and community ecology purposes is challenging, but recent progress has been made. For example, alternative indices to phylogenetic diversity have been proposed to include factors at the origin of shifts in the relation between evolutionary and trait variation.

7. Improving our knowledge on the relation between evolutionary history and trait variation is important as it has implications in various fields of ecology such as the understanding

954 biodiversity to societies.

955

$956 *$ *S7REFERENCES

957

958 Abrams P. 1983. The theory of limiting similarity. Annual Review of Ecology and Systematics $959 \quad 14: 359-376$.

960

961 Avise J. C. 1989. A role for molecular genetics in the recognition and conservation of 962 endangered species. Trends in Ecology and Evolution 4:279-281.

963

964 Billionnet A. 2013. Solution of the generalized Noah's Ark problem. Systematic Biology $965 \quad 62: 147-156$.

967 Bishop R. C. 1978. Endangered species and uncertainty: the economics of a safe minimum 968 standard. American Journal of Agricultural Economics 60:10-18.

970 Blaut M., Clavel T. 2007. Metabolic diversity of the intestinal microbiota: implications for 971 health and disease. Journal of Nutrition 137:751S-755S. 
973 Brooks D. R., Mayden R. L., McLennan D. A. 1992. Phylogeny and biodiversity: conserving 974 our evolutionary legacy. Trends in Ecology and Evolution 7:55-59.

975

976 Cadotte M. W. 2015. Phylogenetic diversity and productivity: gauging interpretations from

977 experiments that do not manipulate phylogenetic diversity. Functional Ecology 29:1603-1606.

979 Cadotte M. W., Davies, J. T. 2010. Rarest of the rare: advances in combining evolutionary

980 distinctiveness and scarcity to inform conservation at biogeographical scales. Diversity and

981 Distributions $16: 376-385$.

982

983 Cadotte M. W., Davies T. J. 2016. Phylogenies in Ecology: A Guide to Concepts and Methods.

984 Princeton (New Jersey): Princeton University Press.

985

986 Cadotte M. W., Davies T. J., Peres-Neto P. R. 2017. Why phylogenies do not always predict

987 ecological differences. Ecological Monographs 87:535-551.

988

989 Cadotte M. W., Davies T. J., Regetz J., Kembel S. W., Cleland E., Oakley T. H. 2010.

990 Phylogenetic diversity metrics for ecological communities: integrating species richness,

991 abundance and evolutionary history. Ecology Letters 13:96-105.

992

993 Cadotte M. W., Tucker C. M. 2018. Difficult decisions: strategies for conservation

994 prioritization when taxonomic, phylogenetic and functional diversity are not spatially congruent.

995 Biological Conservation 225:128-133.

996 
997 Cahill J. F., Kembel S. W., Lamb E. G., Keddy P. A. 2008. Does phylogenetic relatedness

998 influence the strength of competition among vascular plants? Perspectives in Plant Ecology,

999 Evolution and Systematics 10:41-50.

1000

1001 Cavender-Bares J., Ackerly D. D., Baum D. A., Bazzaz F. A. 2004. Phylogenetic overdispersion

1002 in Floridian oak communities. American Naturalist 163:823-843.

1003

1004 Collen B., Turvey S. T., Waterman C., Meredith H. M. R., Kuhn T. S., Baillie J. E. M., Isaac N. J.

1005 B. 2011. Investing in evolutionary history: implementing a phylogenetic approach for mammal

1006 conservation. Philosophical Transactions of the Royal Society B: Biological Sciences 366:2611-

10072622.

1008

1009 Chaudhary A., Vahab P., Mooers A. O. 2018. Projecting global land use-driven evolutionary

1010 history loss. Diversity and Distributions 24:158-167.

1011

1012 Chai Y., Yue M., Liu X., Guo Y., Wang M., Xu J., Zhang C., Chen Y., Zhang L., Zhang R.

1013 2016. Patterns of taxonomic, phylogenetic diversity during a long-term succession of forest on

1014 the Loess Plateau, China: insights into assembly process. Scientific Reports 6:27087.

1015

1016 Cianciaruso M. V., Batalha M. A. Gaston K. J., Petchey O. L. 2009. Including intraspecific

1017 variability in functional diversity. Ecology 90:81-89.

1018

1019 Crozier R. H. 1992. Genetic diversity and the agony of choice. Biological Conservation 61:11102015.

1021 
1022 Crozier R. H., Kusmierski R. M. 1994. Genetic distances and the setting of conservation

1023 priorities. Pages 227-237 in Conservation Genetics, edited by V. Loeschcke, S. K. Jain, and J.

1024 Tomiuk. Basel (Switzerland): Birkhäuser.

1025

1026 Daru B. H., Yessoufou K., Mankga L. T., Davies T. J. 2013. A global trend towards the loss of 1027 evolutionarily unique species in mangrove ecosystems. PLOS ONE 8:e66686.

1028

1029 Darwin C. 1859. On The Origin of Species By Means of Natural Selection, or the Preservation

1030 of Favoured Races in the Struggle For Life. London (United Kingdom): John Murray.

1031

1032 Davies T. J., Buckley L. B. 2011. Phylogenetic diversity as a window into the evolutionary and

1033 biogeographic histories of present-day richness gradients for mammals. Philosophical

1034 Transactions of the Royal Society B: Biological Sciences 366:2414-2425.

1035

1036 Davies T. J. 2015. Losing history: how extinctions prune features from the tree of life.

1037 Philosophical Transactions of the Royal Society B: Biological Sciences 370:20140006.

1038

1039 Davies T. J., Urban M. C., Rayfield B., Cadotte M. W., Peres-Neto P. R. 2016. Deconstructing

1040 the relationships between phylogenetic diversity and ecology: a case study on ecosystem

1041 functioning. Ecology 97:2212-2222.

1042

1043 de Bello F., Šmilauer P., Diniz-Filho J. A. F., Carmona C. P., Lososová Z., Herben T.,

1044 Götzenberger L. 2017. Decoupling phylogenetic and functional diversity to reveal hidden

1045 signals in community assembly. Methods in Ecology and Evolution 8:1200-1211.

1046 
1047 Devictor V., Mouillot D., Meynard C., Jiguet F., Thuiller W., Mouquet N. 2010. Spatial

1048 mismatch and congruence between taxonomic, phylogenetic and functional diversity: the need

1049 for integrative conservation strategies in a changing world. Ecology Letters 13:1030-1040.

1050

1051 Díaz S., Demissew S., Carabias J., et al. 2015. The IPBES Conceptual Framework—connecting 1052 nature and people. Current Opinion in Environmental Sustainability 14:1-16.

1053

1054 Diniz-Filho J. A. F., Bini L. M., Rangel T. F., Morales-Castilla I., Olalla-Tárraga M. Á.,

1055 Rodríguez M. Á., Hawkins B. A. 2012. On the selection of phylogenetic eigenvectors for

1056 ecological analyses. Ecography 35:239-249.

1057

1058 Diniz-Filho J. A. F., Loyola R. D., Raia P., Mooers A. O., Bini L. M. 2013. Darwinian shortfalls

1059 in biodiversity conservation. Trends in Ecology and Evolution 28:689-695.

1060

1061 Egan A. N., Crandall K. A. 2006. Theory of phylogenetic estimation. Pages 426-443 in

1062 Evolutionary Genetics: Concepts and Case Studies, edited by C. W. Fox and J. B. Wolf. Oxford

1063 (United Kingdom): Oxford University Press.

1064

1065 Emerson B. C., Gillespie R. G. 2008. Phylogenetic analysis of community assembly and

1066 structure over space and time. Trends in Ecology and Evolution 23:619-630.

1067

1068 Erwin T. L. 1991. An evolutionary basis for conservation strategies. Science 253:750-752.

1069

1070 Faith D. P. 1992. Conservation evaluation and phylogenetic diversity. Biological Conservation $1071 \quad 61: 1-10$. 
1073 Faith D. P. 1994. Genetic diversity and taxonomic priorities for conservation. Biological

1074 Conservation 68:69-74.

1075

1076 Faith D. P. 2015. Phylogenetic diversity, functional trait diversity and extinction: avoiding

1077 tipping points and worst-case losses. Philosophical Transactions of the Royal Society B:

1078 Biological Sciences 370:20140011.

1079

1080 Faith D. P. 2012. Common ground for biodiversity and ecosystem services: the "partial

1081 protection" challenge. F1000Research 1:30.

1082

1083 Faith D. P. 2016a. The PD phylogenetic diversity framework: linking evolutionary history to

1084 feature diversity for biodiversity conservation. Pages 39-56 in Biodiversity Conservation and

1085 Phylogenetic Systematics: Preserving Our Evolutionary Heritage in an Extinction Crisis, edited

1086 by R. Pellens and P. Grandcolas. Cham (Switzerland): Springer.

1087

1088 Faith D. P. 2016b. A general model for biodiversity and its value. Pages 69-85 in The Routledge

1089 Handbook of Philosophy of Biodiversity, edited by J. Garson, A. Plutynski, and S. Sarkar.

1090 Abingdon (United Kingdom): Routledge.

1091

1092 Faith D. P. 2018a. Phylogenetic diversity and conservation evaluation: perspectives on multiple

1093 values, indices, and scales of application. Pages 1-26 in Phylogenetic Diversity: Applications

1094 and Challenges in Biodiversity Science, edited by R. Scherson and D. P. Faith. Cham

1095 (Switzerland): Springer.

1096 
1097 Faith D. P. 2018b. Unreliable perspectives on phylogenetic diversity. Comment on Should we

1098 conserve phylogenetic diversity?, by F. Mazel. Nature Ecology and Evolution

1099 https://natureecoevocommunity.nature.com/users/172273-daniel-p-faith/posts/34023-should-we-

1100 conserve-phylogenetic-diversity\#comment-8982.

1101

1102 Faith D. P., Baker A. M. 2006. Phylogenetic diversity (PD) and biodiversity conservation: some 1103 bioinformatics challenges. Evolutionary Bioinformatics Online 2:121-128.

1104

1105 Faith D. P., Magallón S., Hendry A. P., Conti E., Yahara T., Donoghue M. J. 2010. Evosystem

1106 services: an evolutionary perspective on the links between biodiversity and human well-being.

1107 Current Opinion in Environmental Sustainability 2:66-74.

1108

1109 Faith D. P., Reid C. A. M., Hunter J. 2004. Integrating phylogenetic diversity, complementarity,

1110 and endemism for conservation assessment. Conservation Biology 18:255-261.

1111

1112 Faith D. P., Richards Z. T. 2012. Climate change impacts on the tree of life: changes in

1113 phylogenetic diversity illustrated for Acropora corals. Biology 1:906-932.

1114

1115 Faith D. P., Veron S., Pavoine S., Pellens R. 2018. Indicators for the expected loss of

1116 phylogenetic diversity. Pages 73-92 in Phylogenetic Diversity: Applications and Challenges in

1117 Biodiversity Science, edited by R. Scherson and D. P. Faith. Cham (Switzerland): Springer.

1118

1119 Faith D. P., Walker P. A. 1996. Environmental diversity: on the best-possible use of surrogate 1120 data for assessing the relative biodiversity of sets of areas. Biodiversity and Conservation 5:3991121415. 
1123 Felsenstein J. 1985. Phylogenies and the comparative method. American Naturalist 125:1-15.

1125 Forest F., Crandall K. A., Chase M. W., Faith D. P. 2015. Phylogeny, extinction and

1126 conservation: embracing uncertainties in a time of urgency. Philosophical Transactions of the

1127 Royal Society B: Biological Sciences 370:20140002.

1128

1129 Forest F., Grenyer R., Rouget M., Davies T. J., Cowling R. M., Faith D. P., Balmford A.,

1130 Manning J. C., Procheş Ş., van der Bank M., Reeves G., Hedderson T. A. J., Savolainen V. 2007.

1131 Preserving the evolutionary potential of floras in biodiversity hotspots. Nature 445:757-760.

1132

1133 Forest F., Moat J., Baloch E., Brummitt N. A., Bachman S. P., Ickert-Bond S., Hollingsworth P.

1134 M., Liston A., Little D. P., Mathews S., Rai H., Rydin C., Stevenson D. W., Thomas P., Buerki S.

1135 2018. Gymnosperms on the EDGE. Scientific Reports 8:6053.

1136

1137 Gascon C., Brooks T. M., Contreras-MacBeath T., Heard N., Konstant W., Lamoreux J., Launay

1138 F., Maunder M., Mittermeier R. A., Molur S., Al Mubarak R. K., Parr M. J., Rhodin A. G. J.,

1139 Rylands A. B., Soorae P., Sanderson J. G., Vié J.-C. 2015. The importance and benefits of

1140 species. Current Biology 25:R431-R438.

1141

1142 Gause GF. 1934. Experimental analysis of Vito Volterra's mathematical theory of 1143 the struggle for existence. Science $79: 16-17$.

1144 
1145 Gerhold P., Cahill J. F., Jr., Winter M., Bartish I. V., Prinzing A. 2015. Phylogenetic patterns are

1146 not proxies of community assembly mechanisms (they are far better). Functional Ecology

$1147 \quad 29: 600-614$.

1148

1149 Goberna M., Verdú M. 2016. Predicting microbial traits with phylogenies. The

1150 ISME journal 10(4), 959.

1151

1152 Gómez-Ortiz Y., Domínguez-Vega H., Moreno C. E. 2017. Spatial variation of mammal

1153 richness, functional and phylogenetic diversity in the Mexican transition zone. Community

1154 Ecology 18:121-127.

1155

1156 Grandcolas P., Nattier R., Trewick S. 2014. Relict species: a relict concept? Trends in Ecology 1157 and Evolution 29:655-663.

1158

1159 Grandcolas P., Trewick S. A. 2016. What is the meaning of extreme phylogenetic diversity?

1160 The case of phylogenetic relict species. Pages 99-115 in Biodiversity Conservation and

1161 Phylogenetic Systematics: Preserving Our Evolutionary Heritage in an Extinction Crisis, edited

1162 by R. Pellens and P. Grandcolas. Cham (Switzerland): Springer.

1163

1164 Guindon S., Dufayard J.-F., Lefort V., Anisimova M., Hordijk W., Gascuel O. 2010. New

1165 algorithms and methods to estimate maximum-likelihood phylogenies: assessing the performance

1166 of PhyML 3.0. Systematic Biology 59:307-321.

1167

1168 Harvey P. H., Pagel M. D. 1991. The Comparative Method in Evolutionary Biology. Oxford

1169 (United Kingdom): Oxford University Press. 
1171 Hendry A. P., Kinnison M. T., Heino M., Day T., Smith T. B., Fitt G., Bergstrom C. T.,

1172 Oakeshott J., Jørgensen P. S., Zalucki M. P., Gilchrist G., Southerton S., Sih A., Strauss S.,

1173 Denison R. F., Carroll S. P. 2011. Evolutionary principles and their practical application.

1174 Evolutionary Applications 4:159-183.

1175

1176 Hennig W. 1950. Grundzüge einer Theorie der Phylogenetischen Systematik. Berlin

1177 (Germany): Deutscher Zentralverlag.

1178

1179 Hennig W. 1965. Phylogenetic systematics. Annual Review of Entomology 10:97-116.

1180

1181 Holder M., Lewis P. O. 2003. Phylogeny estimation: traditional and Bayesian approaches.

$1182 \quad$ Nature Reviews Genetics 4:275-284.

1183

1184 Holt R. D., Gaines M. S. 1992. Analysis of adaptation in heterogeneous landscapes:

1185 implications for the evolution of fundamental niches. Evolutionary Ecology 6:433-447.

1186

1187 Hooper D. U., Chapin F. S., III, Ewel J. J., Hector A., Inchausti P., Lavorel S., Lawton J. H.,

1188 Lodge D. M., Loreau M., Naeem S., Schmid B., Setälä H., Symstad A. J., Vandermeer J., Wardle

1189 D. A. 2005. Effects of biodiversity on ecosystem functioning: a consensus of current

1190 knowledge. Ecological Monographs 75:3-35.

1191

1192 Hubbell S. P. 2001. The Unified Neutral Theory of Biodiversity and Biogeography. Princeton

1193 (New Jersey): Princeton University Press.

1194 
1195 Huelsenbeck J. P., Ronquist F., Nielsen R., Bollback J. P. 2001. Bayesian inference of

1196 phylogeny and its impact on evolutionary biology. Science 294:2310-2314.

1197

1198 Iltis H. H .1972. Shepherds leading sheep to slaughter: the extinction of species and the

1199 destruction of ecosystems. Am Biol Teach 34:201-205

1200

1201 IPBES. 2018. Nature's contributions to people and quality of life. Page 41 in Summary For

1202 Policymakers of the Regional Assessment Report on Biodiversity and Ecosystem Services For

1203 Asia and the Pacific of the Intergovernmental Science-Policy Platform on Biodiversity and

1204 Ecosystem Services, edited by M. Karki et al. Bonn (Germany): IPBES Secretariat.

1205

1206 Isaac N. J. B., Turvey S. T., Collen B., Waterman C., Baillie J. E. M. 2007. Mammals on the

1207 EDGE: conservation priorities based on threat and phylogeny. PLOS ONE 2:e296.

1208

1209 IUCN. 1980. World Conservation Strategy: Living Resource Conservation For Sustainable

1210 Development. Gland (Switzerland): International Union for Conservation of Nature and Natural

1211 Resources.

1212

1213 Jetz W., Thomas G. H., Joy J. B., Redding D. W., Hartmann K., Mooers A. O. 2014. Global

1214 distribution and conservation of evolutionary distinctness in birds. Current Biology 24:919-930.

1215

1216 Kelly S., Grenyer R., Scotland R. W. 2014. Phylogenetic trees do not reliably predict feature

1217 diversity. Diversity and Distributions 20:600-612.

1218 
1219 Kraft N. J. B., Cornwell W. K., Webb C. O., Ackerly D. D. 2007. Trait evolution, community

1220 assembly, and the phylogenetic structure of ecological communities. American Naturalist

$1221 \quad 170: 271-283$.

1222

1223 Larsen F. W., Turner W. R., Brooks, T. M. 2012. Conserving critical sites for

1224 biodiversity provides disproportionate benefits to people. PLoS One, 7(5), 1225 e36971.

1226

1227 Lean C., Maclaurin J. 2016. The value of phylogenetic diversity. Pages 19-37 in Biodiversity

1228 Conservation and Phylogenetic Systematics: Preserving Our Evolutionary Heritage in an

1229 Extinction Crisis, edited by R. Pellens and P. Grandcolas. Cham (Switzerland): Springer.

1231 Lemey P., Salemi M., Vandamme A.-M. 2009. The Phylogenetic Handbook: A Practical

1232 Approach to Phylogenetic Analysis and Hypothesis Testing. Second Edition. Cambridge (United

1233 Kingdom): Cambridge University Press.

1234

1235 Lozupone C. A., Stombaugh J. I., Gordon J. I., Jansson J. K., Knight R. 2012. Diversity,

1236 stability and resilience of the human gut microbiota. Nature 489:220-230.

1237

1238 Letten A. D., Cornwell W. K. 2015. Trees, branches and (square) roots: why evolutionary

1239 relatedness is not linearly related to functional distance. Methods in Ecology and Evolution

$1240 \quad 6: 439-444$.

1241 
1242 Loreau M., Naeem S., Inchausti P., Bengtsson J., Grime J. P., Hector A., Hooper D. U., Huston

1243 M. A., Raffaelli D., Schmid B., Tilman D., Wardle D. A. 2001. Biodiversity and ecosystem

1244 functioning: current knowledge and future challenges. Science 294:804-808.

1245

1246 Losos J. B. 2008. Phylogenetic niche conservatism, phylogenetic signal and the relationship

1247 between phylogenetic relatedness and ecological similarity among species. Ecology Letters

$1248 \quad 11: 995-1003$.

1249

1250 Losos J. B. 2011. Seeing the forest for the trees: the limitations of phylogenies in comparative

1251 biology (American Society of Naturalists Address). American Naturalist 177:709-727.

1252

1253 Lotka A. J. 1925. Elements of Physical Biology. Baltimore (Maryland): Williams and Wilkins

1254 Company.

1255

1256 Macarthur R., Levins R. 1967. The limiting similarity, convergence, and divergence of

1257 coexisting species. American Naturalist 101:377-385.

1258

1259 Mace G. M., Gittleman J. L., Purvis A. 2003. Preserving the tree of life. Science 300:1707-

12601709.

1261

1262 Mace G. M., Reyers B., Alkemade R., Biggs R., Chapin F. S., III, Cornell S. E., Diaz S., Jennings

1263 S., Leadley P., Mumby P. J., Purvis A., Scholes R. J., Seddon A. W. R., Solan M., Steffen W.,

1264 Woodward G. 2014. Approaches to defining a planetary boundary for biodiversity. Global

1265 Environmental Change 28:289-297.

1266 
1267 Maclaurin J., Sterelny K. 2008. What is Biodiversity? Chicago (Illinois): University of Chicago 1268 Press.

1269

1270 Magnuson-Ford K., Ingram T., Redding D. W., Mooers A. Ø. 2009. Rockfish (Sebastes) that are 1271 evolutionarily isolated are also large, morphologically distinctive and vulnerable to overfishing.

1272 Biological Conservation 142:1787-1796.

1273

1274 Margules C. R., Pressey R. L. 2000. Systematic conservation planning. Nature 405 :243.

1275

1276 Mason N. W. H., Pavoine S. 2013. Does trait conservatism guarantee that indicators of

1277 phylogenetic community structure will reveal niche-based assembly processes along stress

1278 gradients? Journal of Vegetation Science 24:820-833.

1279

1280 May R. M. 1990. Taxonomy as destiny. Nature 347:129-130.

1281

1282 Mayfield M. M., Levine J. M. 2010. Opposing effects of competitive exclusion on the 1283 phylogenetic structure of communities. Ecology Letters 13:1085-1093.

1284

1285 Mazel F., Davies T. J., Georges D., Lavergne S., Thuiller W., Peres-Neto P. R. 2016. Improving 1286 phylogenetic regression under complex evolutionary models. Ecology 97:286-293.

1287

1288 Mazel F., Wüest R. O., Gueguen M., Renaud J., Ficetola G. F., Lavergne S., Thuiller W. 2017.

1289 The geography of ecological niche evolution in mammals. Current Biology 27:1369-1374.

1290 
1291 Mazel F., Pennel M., Cadotte M., Díaz S., Dalla Riva G., Grenyer R., Leprieur F., Mooers A.,

1292 Mouillot D., Tucker C., Pearse W. 2018. Is phylogenetic diversity a surrogate for functional

1293 diversity across clades and space? bioRxiv:243923.

1294

1295 Millennium Ecosystem Assessment. 2005. Ecosystems and Human Well-Being: Biodiversity

1296 Synthesis. Washington(DC): World Resources Institute.

1297

1298 Morlon H., Potts M. D., Plotkin J. B. 2010. Inferring the dynamics of diversification: a

1299 coalescent approach. PLOS Biology 8:e1000493.

1300

1301 Mouillot D., Parravicini V., Bellwood D. R., Leprieur F., Huang D., Cowman P. F., Albouy C.,

1302 Hughes T. P., Thuiller W., Guilhaumon F. 2016. Global marine protected areas do not secure the

1303 evolutionary history of tropical corals and fishes. Nature Communications 7:10359.

1304

1305 Mouquet N., Devictor V., Meynard C. N., et al. 2012. Ecophylogenetics: advances and

1306 perspectives. Biological Reviews 87:769-785.

1307

1308 Myers N., Mittermeier R. A., Mittermeier C. G., Da Fonseca G. A., Kent J. 2000.

1309 Biodiversity hotspots for conservation priorities. Nature 403, 853.

1310

1311 Nguyen L.-T., Schmidt H. A., von Haeseler A., Minh B. Q. 2014. IQ-TREE: a fast and effective

1312 stochastic algorithm for estimating maximum-likelihood phylogenies. Molecular Biology and

1313 Evolution 32:268-274.

1314 
1315 Nei M. 1991. Relative efficiencies of different tree-making methods for molecular data. Pages

1316 90-128 in Phylogenetic Analyses of DNA Sequences, edited by M. M. Miyamoto and J. Cracraft.

1317 Oxford (United Kingdom): Oxford University Press.

1318

1319 Nunes L. A., Turvey S. T., Rosindell J. 2015. The price of conserving avian phylogenetic

1320 diversity: a global prioritization approach. Philosophical Transactions of the Royal Society B:

1321 Biological Sciences 370:20140004.

1322

1323 Oka C., Aiba M., Nakashizuka T. 2019. Phylogenetic clustering in beneficial attributes of tree

1324 species directly linked to provisioning, regulating and cultural ecosystem services. Ecological

1325 Indicators 96:477-495.

1326

1327 Oliver T. H. 2016. How much biodiversity loss is too much? Science 353:220-221.

1328

1329 Pagel M. 1999. Inferring the historical patterns of biological evolution. Nature 401:877-884.

1331 Pavoine S., Bonsall M. B. 2011. Measuring biodiversity to explain community assembly: a

1332 unified approach. Biological Reviews 86:792-812.

1333

1334 Pavoine S., Gasc A., Bonsall M. B., Mason N. W. H. 2013. Correlations between phylogenetic

1335 and functional diversity: mathematical artefacts or true ecological and evolutionary processes?

1336 Journal of Vegetation Science 24:781-793.

1337

1338 Pavoine S., Ollier S., Dufour A.-B. 2005. Is the originality of a species measurable? Ecology 1339 Letters 8:579-586. 
1341 Pearse W. D., Legendre P., Peres-Neto P., Davies J. 2018. The interaction of phylogeny and

1342 community structure: linking clades' ecological structures and trait evolution. bioRxiv:404111.

1344 Pollock L. J., Thuiller W., Jetz W. 2017. Large conservation gains possible for global

1345 biodiversity facets. Nature 546:141-144.

1346

1347 Redding D. W., DeWolff C. V., Mooers A. Ø. 2010. Evolutionary distinctiveness, threat status, 1348 and ecological oddity in primates. Conservation Biology 24:1052-1058.

1350 Redding D. W., Hartmann K., Mimoto A., Bokal D., DeVos M., Mooers A. Ø. 2008.

1351 Evolutionarily distinctive species often capture more phylogenetic diversity than expected.

1352 Journal of Theoretical Biology 251:606-615.

1353

1354 Redding D. W., Mooers A. Ø. 2006. Incorporating evolutionary measures into conservation 1355 prioritization. Conservation Biology 20:1670-1678.

1357 Rizzo J., Rouchka E. C. 2007. Review of phylogenetic tree construction. University of 1358 Louisville Bioinformatics Laboratory Technical Report TR-ULBL-2007-01.

1360 Rolland J., Cadotte M. W., Davies J., Devictor V., Lavergne S., Mouquet N., Pavoine S., 1361 Rodrigues A., Thuiller W., Turcati L., Winter M., Zupan L., Jabot F., Morlon H. 2012. Using 1362 phylogenies in conservation: new perspectives. Biology Letters 8:692-694.

1363 
1364 Rosauer D., Laffan S. W., Crisp M. D., Donnellan S. C., Cook L. G. 2009. Phylogenetic

1365 endemism: a new approach for identifying geographical concentrations of evolutionary history.

1366 Molecular Ecology 18:4061-4072.

1368 Rosauer D. F., Pollock L. J., Linke S., Jetz W. 2017. Phylogenetically informed spatial planning

1369 is required to conserve the mammalian tree of life. Proceedings of the Royal Society B:

1370 Biological Sciences 284:20170627.

1371

1372 Safi K., Armour-Marshall K., Baillie J. E. M., Isaac N. J. B. 2013. Global patterns of

1373 evolutionary distinct and globally endangered amphibians and mammals. PIOS ONE 8:e63582.

1374

1375 Saito V. S., Valente-Neto F., Rodrigues M. E., de Oliveira Roque F., Siqueira T. 2016.

1376 Phylogenetic clustering among aggressive competitors: evidence from odonate assemblages

1377 along a riverine gradient. Oecologia 182:219-229.

1378

1379 Saito V. S., Laroche F., Siqueira T., Pavoine S. 2018. Ecological versatility and the assembly of

1380 multiple competitors: cautionary notes for assembly inferences. Ecology 99:1173-1183.

1381

1382 Saitou N., Nei M. 1987. The neighbor-joining method: a new method for reconstructing

1383 phylogenetic trees. Molecular Biology and Evolution 4:406-425.

1384

1385 Sarrazin F., Lecomte J. 2016. Evolution in the Anthropocene. Science 351:922-923.

1386

1387 Steel M., Mimoto A., Mooers A. 2007. Hedging our bets: the expected contribution of species to 1388 future phylogenetic diversity. Evol. Bioinformatics Online 3:237-244. 
1390 Stein R. W., Mull C. G., Kuhn T. S., Aschliman N. C., Davidson L. N. K., Joy, J. B., Smith G. J.,

1391 Dulvy N. K., Mooers A. O. 2018. Global priorities for conserving the evolutionary history of 1392 sharks, rays and chimaeras. Nature Ecology and Evolution 2:288-298.

1394 Srivastava D. S., Cadotte M. W., MacDonald A. A. M., Marushia R. G., Mirotchnick N. 2012.

1395 Phylogenetic diversity and the functioning of ecosystems. Ecology Letters 15:637-648.

1397 Stamatakis A. 2006. RAxML-VI-HPC: maximum likelihood-based phylogenetic analyses with 1398 thousands of taxa and mixed models. Bioinformatics 22:2688-2690.

1400 Tamura K., Peterson D., Peterson N., Stecher G., Nei M., Kumar S. 2011. MEGA5: molecular 1401 evolutionary genetics analysis using maximum likelihood, evolutionary distance, and maximum 1402 parsimony methods. Molecular Biology and Evolution 28:2731-2739.

1403

1404 Thévenin C., Mouchet M., Robert A., Kerbiriou C., Sarrazin F. 2018. Reintroductions of birds 1405 and mammals involve evolutionarily distinct species at the regional scale. Proceedings of the 1406 National Academy of Sciences of the United States of America 115:3404-3409.

1408 Trewick S. A., Morgan-Richards M. 2016. Phylogenetics and conservation in New Zealand: the 1409 long and the short of it. Pages 81-97 in Biodiversity Conservation and Phylogenetic Systematics:

1410 Preserving Our Evolutionary Heritage in an Extinction Crisis, edited by R. Pellens and P.

1411 Grandcolas. Cham (Switzerland): Springer.

1412 
1413 Tribot A.-S., Mouquet N., Villéger S., Raymond M., Hoff F., Boissery P., Holon F., Deter J.

1414 2016. Taxonomic and functional diversity increase the aesthetic value of coralligenous reefs.

1415 Scientific Reports 6:34229.

1416

1417 Tucker C. M., Cadotte M. W., Carvalho S. B., Davies T. J., Ferrier S., Fritz S. A., Grenyer R.,

1418 Helmus M. R., Jin L. S., Mooers A. O., Pavoine S., Purschke O., Redding D. W., Rosauer D. F.,

1419 Winter M., Mazel F. 2017. A guide to phylogenetic metrics for conservation, community

1420 ecology and macroecology. Biological Reviews 92:698-715.

1421

1422 Tucker C. M., Davies T. J., Cadotte M. W., Pearse W. D. 2018. On the relationship between

1423 phylogenetic diversity and trait diversity. Ecology 99:1473-1479.

1424

1425 Vamosi J. C., Vamosi S. M. 2007. Body size, rarity, and phylogenetic community structure:

1426 insights from diving beetle assemblages of Alberta. Diversity and Distributions 13:1-10.

1427

1428 Vane-Wright R. I., Humphries C. J., Williams P. H. 1991. What to protect?-systematics and

1429 the agency of choice. Biological Conservation 55:235-254.

1430

1431 Venail P., Gross K., Oakley T. H., Narwani A., Allan E., Flombaum P., Isbell F., Joshi J., Reich

1432 P. B., Tilman D., van Ruijven J., Cardinale B. J. 2015. Species richness, but not phylogenetic

1433 diversity, influences community biomass production and temporal stability in a re-examination of

143416 grassland biodiversity studies. Functional Ecology 29:615-626.

1435

1436 Veron S., Clergeau P., Pavoine S. 2016. Loss and conservation of evolutionary history in the 1437 Mediterranean Basin. BMC Ecology 16:43. 
1439 Veron S., Davies T. J., Cadotte M. W., Clergeau P., Pavoine S. 2017. Predicting loss of

1440 evolutionary history: where are we? Biological Reviews 92:271-291.

1442 Veron S., Faith D. P., Pellens R., Pavoine S. 2018. Priority areas for phylogenetic diversity:

1443 maximising gains in the Mediterranean basin. Pages 145-166 in Phylogenetic Diversity:

1444 Applications and Challenges in Biodiversity Science, edited by R. Scherson and D. P. Faith.

1445 Cham (Switzerland): Springer.

\section{6}

1447 Volterra V. 1926. Fluctuations in the abundance of a species considered mathematically. Nature $1448 \quad 118: 558-560$.

1450 Voskamp A., Baker D. J., Stephens P. A., Valdes P. J., Willis S. G. 2017. Global patterns in the 1451 divergence between phylogenetic diversity and species richness in terrestrial birds. Journal of 1452 Biogeography 44:709-721.

1453

1454 Webb C. O., Ackerly D. D., McPeek M. A., Donoghue M. J. 2002. Phylogenies and community 1455 ecology. Annual Review of Ecology and Systematics 33:475-505.

1457 Weitzman M. L. 1992. On diversity. Quarterly Journal of Economics 107:363-405.

1459 Wiens J. J., Graham C. H. 2005. Niche conservatism: integrating evolution, ecology, and 1460 conservation biology. Annual Review of Ecology, Evolution, and Systematics 36:519-539. 
1462 Williams P. H., Humphries C. J. 1994. Biodiversity, taxonomic relatedness, and endemism in 1463 conservation. Pages 269-287 in Systematics Association Special Volume 50: Systematics and

1464 Conservation Evaluation, edited by P. L. Forey, C. J. Humphries, and R. I. Vane-Wright. Oxford 1465 (United Kingdom): Clarendon Press.

1466

1467 Winter M., Devictor V., Schweiger O. 2013. Phylogenetic diversity and nature conservation:

1468 where are we? Trends in Ecology and Evolution 28:199-204.

1469

1470 Witting L., Loeschcke V. 1995. The optimization of biodiversity conservation. Biological 1471 Conservation 71:205-207.

1472

1473 Yguel B., Bailey R., Tosh N. D., Vialatte A., Vasseur C., Vitrac X., Jean F., Prinzing A. 2011.

1474 Phytophagy on phylogenetically isolated trees: why hosts should escape their relatives. Ecology 1475 Letters 14:1117-1124.

1476

1477 Yguel B., Bailey R. I., Villemant C., Brault A., Jactel H., Prinzing A. 2014. Insect herbivores

1478 should follow plants escaping their relatives. Oecologia 176:521-532.

1479

1480 Yguel B., Jactel H., Pearse I. S., Moen D., Winter M., Hortal J., Helmus M. R., Kühn I., Pavoine

1481 S., Purschke O., Weiher E., Violle C., Ozinga W., Brändle M., Bartish I., Prinzing A. 2016. The 1482 evolutionary legacy of diversification predicts ecosystem function. American Naturalist

$1483 \quad 188: 398-410$.

1484

1485 APPENDIX 1

1486 
1488 Character: All observable characters of an organism, including morphological, anatomical, 1489 chemical, and molecular.

1490 Diversification: The process that lead species to diversify; the sum of speciation and extinction 1491 events.

1492 Evolutionary History: The history of species evolution that links all species on Earth in a

1493 unique natural classification.

1494 Extinction: In its modern definition, a species is considered extinct when there is no reasonable 1495 doubt that the last individual has died.

1496 Natural Selection: Darwin's natural selection theory stated that the most useful variations of 1497 species in their environment (i.e., a new fitness) favored the individuals and thus persisted, and 1498 that those advantageous variations were inheritable.

1499 Niche Complementarity: This hypothesis states that for coexistence to occur high overlap in one 1500 dimension of the niche must be compensated by low overlap in another.

1501 Option Value: Biodiversity values that provide benefits and uses, often unanticipated, for future 1502 generations.

1503 Operational Taxonomic Unit (OTU): An operational definition used to classify groups of 1504 closely related individuals.

1505 Phylogenetic Root: The root represents the common ancestor to all taxa on a tree and is their 1506 oldest ancestor.

1507 Phylogenetic Signal: The tendency for related species to resemble each other more than they 1508 resemble species drawn at random from the phylogenetic tree.

1509 Species: Defined for language convention as reproductively isolated populations.

1510 Speciation: Lineage-splitting event that produces two or more separate species. 
1511 Trait: The diversity of morphological, biochemical, behavioral, and physiological characters of 1512 species.

1513 Tree of Life: Phylogenetic tree depicting the links uniting all of the species on Earth. 